\title{
Effective role of the 'loading' dose of magnesium sulfate in the treatment of eclampsia
}

\author{
Halima Khatun ${ }^{1 *}$, M. Saiful Islam², Tarikul Islam
}

\author{
${ }^{1}$ Department of Obstetrics and Gynecology, ${ }^{2}$ Department of Radiology and Imagine, Rajshahi Medical College \\ Hospital, Rajshahi, Bangladesh \\ ${ }^{3}$ Department of Burn and Plastic Surgery, Khulna Medical College Hospital, Khulna, Bangladesh
}

Received: 08 February 2021

Accepted: 31 March 2021

\section{*Correspondence:}

Dr. Halima Khatun,

E-mail: kariul@hotmail.com

Copyright: (c) the author(s), publisher and licensee Medip Academy. This is an open-access article distributed under the terms of the Creative Commons Attribution Non-Commercial License, which permits unrestricted non-commercial use, distribution, and reproduction in any medium, provided the original work is properly cited.

\begin{abstract}
Background: Eclampsia is defined as the occurrence of one or more convulsions in association with the syndrome of preeclampsia. In Bangladesh, eclampsia is the $3^{\text {rd }}$ major cause of maternal death. Magnesium sulfate is now the drug of choice for women with eclampsia for controlling convulsion with strong evidence that it is better than diazepam, phenytoin or lytic cocktail. Aim of the study was to find out the effective role of loading dose of magnesium sulfate in the treatment of the convulsion in eclampsia.

Methods: Prospective comparative study. In the Department of Obstetrics and Gynaecology, Rajshahi Medical College Hospital (RMCH)" from January 2008 to December 2008. A total of 100 eclamptic patients who are eligible for magnesium sulfate therapy were purposively assigned to receive either only loading "dose or traditional dose for control of convulsion. Data was organized and the results were presented in tables, figures, diagram etc. by using SPSS-10 and MS-Excel 2016.

Results: The mean $( \pm \mathrm{SD})$ convulsion (fit) and delivery interval was $7.95 \pm 1.33$. Regained consciousness was predominant $28(56.0 \%)$ patients after initiation of treatment. Maternal death was found $1(2.00 \%)$. The cause of maternal mortality was due to renal failure. The mean $( \pm \mathrm{SD})$ respiratory rate was $20.2 \pm 4.19 \mathrm{~min}$. Normal urine was found $43(86.0 \%)$. Normal knee jerks were found $45(90.0 \%)$. No toxicity developed in any group assessed by the parameters like respiratory rate, urine volume and knee jerks.

Conclusions: For the above reasons eclampsia can be treated effectively by only loading dose of $\mathrm{Mgs}_{4}$ in primary as well as tertiary level hospital which will significantly reduce the maternal morbidity and mortality.
\end{abstract}

Keywords: Convulsion, Eclampsia, Magnesium sulfate $\left(\mathrm{MgSO}_{4}\right)$, Preeclampsia

\section{INTRODUCTION}

Preeclampsia eclampsia is a disease in which all the organs of the body are affected and show more or less pathological changes. ${ }^{1}$ Eclampsia is defined as the occurrence of one or more convulsions in association with the syndrome of preeclampsia. ${ }^{2}$ The term 'eclampsia' is derived from a Greek word meaning like a flash of lightening as it may occur quite abruptly without any warning manifestation. But usually the disease is preceded by features of severe preeclampsia. Preeclampsia is hypertension associated with proteinuria and oedema, occurring primarily in nulliparous after the $20^{\text {th }}$ gestational week and most frequently near term, although recent data support the elimination of oedema as a diagnostic criterion. ${ }^{3}$ The pathogenesis of eclamptic convulsions continues to be the subject of extensive investigation and speculation. Several theories and aetiologic mechanisms have been implicated as possible aetiologic factors, but none of these have been conclusively proven. Some of the aetiologic mechanisms 
that are implicated in the pathogenesis of eclamptic convulsions have included cerebral vasoconstriction or vasospasm, hypertensive encephalopathy, cerebral oedema or infarction, cerebral haemorrhage and metabolic encephalopathy. However, it is not clear whether these findings are causes or are effects of the convulsions. So, eclampsia is no doubt a complex disease the pathogenesis of which is not completely understood. Cerebral involvement causing convulsions can kill the mother and featus unless expertly managed1. In Bangladesh, eclampsia is the $3^{\text {rd }}$ major cause of maternal death. ${ }^{4}$ Magnesium sulfate has emerged as the anticonvulsant of choice for the treatment of women with eclampsia and the limitations and side effects of diazepam and phenytoin need to be reconsidered. The results of the Magpie Trial (Magnesium Sulfate for Prevention of Eclampsia) were again impressive revealing that preventive magnesium sulfate for all severe cases of preeclampsia can reduce the risk of development of eclampsia and maternal death by 58 and 45 percent, respectively. ${ }^{1}$ The superiority of magnesium sulfate for the treatment of eclampsia was clearly demonstrated by the publication of the collaborative eclampsia trial in 1995. At about the same time, a smaller, pilot study was conducted at Dhaka Medical College Hospital (DMCH) between May 1995 and June 1996, which came to exactly the same conclusions regarding the drug. The main difference between the two studies was the dosage regime of magnesium sulfate.

The loading dose used in DMCH was significantly less than, that used by the Collaborative Eclampsia Trial ( $10 \mathrm{~g}$ loading dose compared to $14 \mathrm{~g}$ ). Maintenance treatment, hereafter, was also half the dose $(2.5 \mathrm{~g}$ of $5 \mathrm{~g})$. The lower dosage had been chosen principally because of the small size of Bangladeshi women and concerns about toxicity in circumstances in which measuring serum levels of magnesium would be difficult. Considering the evidence from these studies, magnesium sulfate was chosen to replace diazepam by a national working group on eclampsia in October 1997 and it was agreed that the regime validated for local use would be recommended for nation-al use. ${ }^{5}$ Guidelines were prepared and disseminated.

In $\mathrm{RMCH}$ and in the other tertiary level hospitals, policies were immediately changed. Thereafter, from the beginning of 1998, magnesium sulfate is being used as a routine anticonvulsant in $\mathrm{RMCH}$ since its local production began. The study aims to find out the effective role of loading dose of magnesium sulfate in the treatment of the convulsion in eclampsia.

General objective of the study was to find out the effective role of 'loading' dose of magnesium sulfate in the treatment of the convulsion in eclampsia.

Specific objectives of the study was to determine the effects of loading dose of $\mathrm{MgSO}_{4}$ on control of convulsion and to find out the outcomes and side effects of magnesium sulfate of the patients.

\section{METHODS}

This was a cross sectional study and was conducted in the Department of Obstetrics and Gynecology in Rajshahi Medical College Hospital, Rajshahi, Bangladesh during the period January 2008 to December 2008. Purposive Sampling technique used for this study, then 50 ecliptic patients fulfilling the inclusion criteria were purposively included in this study. Patients were included who received loading dose (10gm) of magnesium sulfate only for 24 hours after the last convulsion 'or delivery.

\section{Inclusion criteria}

Eclamptic patients with gestational period beyond 2.8 weeks.

\section{Exclusion criteria}

Gestational period less than 28 weeks, eclamptic patients in whom magnesium sulfate therapy is contraindicated (i.e. oliguria, renal failure, absent deep tendon reflex, respiratory rate $<16 / \mathrm{m}$ ) comatose patients and patients who received $\mathrm{MgSO}_{4}$ from outside.

Eclamptic cases were selected from the 'Department of Obstetrics and Gynaecology of Rajshahi Medical Collage Hospital (RMCH) during the study period was investigated. Patients who met the selection criteria of the study were identified during admission, then they were purposively assigned to receive either loading dose of $\mathrm{MgSO}_{4}$ or 'traditional dose' (loading plus maintenance dose), possible effects and out comes in two groups were observed. Maternal outcomes were measured by recurrence of convulsion, time taken to control fit, time taken to regain consciousness, presence or absence of maternal complications e.g., pulmonary oedema, renal failure, DIC, HELLP syndrome and maternal death.

Fetal outcomes were measured by APGAR rating at birth. For all women detailed history, physical examination, necessary and available investigations were carried out. Data were collected in a predesigned structured data collection sheets. Data was organized and the results were presented in tables, figures, diagram etc by using SPSS-10 and MS-Excel 2016.

\section{RESULTS}

The mean $( \pm \mathrm{SD})$ age found in the study was $25.92 \pm 5.63$ years. Maximum number was found in the age group of 26-30 years in the study. None of the patients were from the higher socioeconomic status. 16 percent of the patient were admitted to the hospital with term (>37 weeks) pregnancy. The mean $( \pm \mathrm{SD})$ gestational age was $35.14 \pm 2.49$ respectively (Table 1 ). 
Table 1: Patient's profile of the study patients $(\mathrm{N}=50)$.

\begin{tabular}{|c|c|c|c|}
\hline \multicolumn{2}{|c|}{$\begin{array}{l}\text { Demographic } \\
\text { characteristics }\end{array}$} & $\mathbf{n}$ & $\%$ \\
\hline \multirow{5}{*}{$\begin{array}{l}\text { Age } \\
\text { (years) }\end{array}$} & $\leq 20$ & 12 & 24.0 \\
\hline & $21-25$ & 11 & 22.0 \\
\hline & $26-30$ & 17 & 34.0 \\
\hline & $>30$ & 10 & 20.0 \\
\hline & Mean \pm SD & 25. & \\
\hline \multirow{6}{*}{$\begin{array}{l}\text { Socio- } \\
\text { economic } \\
\text { status }\end{array}$} & Low & 38 & 76.0 \\
\hline & Middle & 12 & 24.0 \\
\hline & Parity & 11 & 22.0 \\
\hline & Primi & 17 & 34.0 \\
\hline & Multi & 10 & 20.0 \\
\hline & $\begin{array}{l}\text { Grand } \\
\text { multi }\end{array}$ & 3 & 6.0 \\
\hline \multirow{4}{*}{$\begin{array}{l}\text { Gastation } \\
\text { age (wks) }\end{array}$} & $\leq 32$ & 9 & 18.0 \\
\hline & $33-37$ & 33 & 66.0 \\
\hline & $>37$ & 8 & 16.0 \\
\hline & Mean \pm SD & 35. & \\
\hline
\end{tabular}

Table 2: Physical findings during admission of the study patients $(\mathrm{N}=\mathbf{5 0})$.

\begin{tabular}{|llll|}
\hline Physical conditions & n & $\%$ \\
\hline \multirow{2}{*}{$\begin{array}{l}\text { Level of } \\
\text { consciousness }\end{array}$} & Conscious & 15 & 30.0 \\
\cline { 2 - 4 } & Semiconscious & 27 & 54.0 \\
\cline { 2 - 4 } & Unconscious & 8 & 16.0 \\
\hline Oedema & Nil & 6 & 12.0 \\
\cline { 2 - 4 } & Mild & 21 & 42.0 \\
\cline { 2 - 4 } & Moderate & $1 \cdot 9$ & 38.0 \\
\cline { 2 - 4 } & Severe & 4 & 8.0 \\
\hline Urinary & Nil & 4 & 8.0 \\
\cline { 2 - 4 } albumin & Mild & 24 & 48.0 \\
\cline { 2 - 4 } & Moderate & 20 & 40.0 \\
\cline { 2 - 4 } & Severe & 2 & 4.0 \\
\hline $\begin{array}{l}\text { Systolic blood } \\
\text { presser }\end{array}$ & Mean \pm SD & $153.4 \pm 21.6$ \\
\hline $\begin{array}{l}\text { Diastolic blood } \\
\text { pressure }\end{array}$ & Mean \pm SD & $105.0 \pm 14.4$ \\
\hline
\end{tabular}

About one third $15(30.00 \%)$ patients were presented in the conscious state respectively $27(54.0 \%)$ in semiconscious and $8(16.0 \%)$ in Unconscious.

It was observed that semiconscious $27(54.0 \%)$, mild oedema 21(42.0\%) and mild urinary albumin 24(48\%) were predominant. Mean blood pressure was 153.4 \pm 21.6 in systolic and 105.0 \pm 14.4 in diastolic (Table 2).

The mean $( \pm$ SD) number of convulsion (before admission) was $6.08 \pm 1.86$. The mean $( \pm \mathrm{SD})$ convulsion (fit) and admission interval was $5.98 \pm 1.20$. In the mean $( \pm \mathrm{SD})$ convulsion and treatment interval was $6.23 \pm 1.18$ hours. The mean $( \pm \mathrm{SD})$ convulsion (fit) and delivery interval was $7.95 \pm 1.33$ (Table 3 ).
Table 3: Distribution of convulsion before and after treatment of eclampsia $(\mathrm{N}=50)$.

\begin{tabular}{|ll|}
\hline Variables & Mean \pm SD \\
\hline No of convulsion (before admission) & $6.08 \pm 1.86$ \\
\hline $\begin{array}{l}\text { Convulsion (fit) and admission } \\
\text { interval }\end{array}$ & $5.98 \pm 1.2$ \\
\hline Convulsion and treatment interval & $6.23 \pm 1.18$ \\
\hline Convulsion (fit) and delivery interval & $7.95 \pm 1.33$ \\
\hline
\end{tabular}

Recurrence of convulsion were, found $4(8.00 \%)$ and number of convulsion one was found in $1(2.0 \%)$. However, no. of convulsion two was found $3(6.0 \%)$. One hour taken after control of convulsion was $2(4.0 \%)$ patients.

Two hours- taken after control of convulsion was $2(4.00 \%)$. Monitoring of the patients to detect the toxicity of loading dose of $\mathrm{MgSO}_{4}$ in both groups at $1^{\text {st }}$ to $3^{\text {rd }}$ hours and 24 hours after the initiation of treatment was done (Table 4).

Table 4: Recurrence of convulsion after initiation of treatment of eclampsia $(\mathrm{N}=50)$.

\begin{tabular}{|llll|}
\hline Variables & n & \% \\
\hline $\begin{array}{l}\text { Recurrence of } \\
\text { convulsion }\end{array}$ & Yes & 4 & 8.0 \\
\cline { 2 - 4 } Number of & No & 46 & 92.0 \\
\hline $\begin{array}{l}\text { convulsion } \\
\text { Time taken after } \\
\text { control of convulsion } \\
\text { (hrs. b ) }\end{array}$ & 1 & 1 & 2.0 \\
\cline { 2 - 4 } & 2 hour & 2 & 6.0 \\
\hline
\end{tabular}

Table 5: Maternal outcome after treatment of eclampsia $(\mathbf{N}=50)$.

\begin{tabular}{|llll|}
\hline Maternal outcome after treatment & n & $\%$ \\
\hline & $\begin{array}{l}\text { Remained } \\
\text { consciousness }\end{array}$ & 20 & 40.0 \\
\cline { 2 - 4 } $\begin{array}{l}\text { State of } \\
\text { consciousness }\end{array}$ & $\begin{array}{l}\text { Remained } \\
\text { unconsciousness }\end{array}$ & 2 & 4.0 \\
\cline { 2 - 4 } & $\begin{array}{l}\text { Regained } \\
\text { consciousness }\end{array}$ & 28 & 56.0 \\
\hline $\begin{array}{l}\text { Maternal } \\
\text { death/Mortality }\end{array}$ & 2 & 49 & 98.0 \\
\hline Morbidity & 1 hour & 1 & 2.0 \\
\hline & 2 hour & 34 & 32.0 \\
\hline
\end{tabular}

Regained consciousness was predominant 28 (56.0\%) patients after initiation of treatment. Maternal death was found $1(2.00 \%)$. The cause of maternal mortality was due to renal failure (Table 5).

The mean $( \pm \mathrm{SD})$ respiratory rate was $20.2 \pm 4.19$ minute. Normal urine was found $43(86.0 \%)$. Normal knee jerks were found $45(90.0 \%)$. No toxicity developed in any 
group assessed by the parameters like respiratory rate, urine volume and knee jerks (Table 6).

Table 6: Monitoring of the patients to detect toxicity of $\mathrm{MgSO}_{4}(\mathrm{n}=50)$.

\begin{tabular}{|lll|}
\hline Variables & n & $\%$ \\
\hline $\begin{array}{l}\text { Respiratory rate (minute) } \\
\text { urine }\end{array}$ & $20.2 \pm 4.19$ & \\
\hline Normal & 43 & 86.0 \\
\hline Oliguria & 7 & 14.0 \\
\hline Normal knee jerks & 45 & 90.0 \\
\hline Exaggerated knee jerks & 5 & 10.0 \\
\hline Absent knee jerks & 0 & 0.0 \\
\hline
\end{tabular}

\section{DISCUSSION}

Eclampsia is a multi-system disorder with complex pathogenesis, which is flat completely understood. ${ }^{6}$ Control of convulsion and prevention of recurrence is one of the most important part of management of eclampsia. There is no conclusive evidence that the best available treatment for women who have had an ecliptic fit is magnesium sulfate. Bangladesh is a developing country where the incidence of eclampsia is very high and eclampsia remains the leading cause of death in large tertiary level hospitals, like Rajshahi Medical College Hospital (RMCH) for many years. ${ }^{7} \mathrm{MgSO}_{4}$ has been used as a routine anti-convulsant in many obstetric centers of Bangladesh since 1998. But the dose that is recommended by Bangladesh eclampsia working group is much lower than that used in the eclampsia collaborative trial (10gm loading dose compared to $14 \mathrm{gm}$ and $2.5 \mathrm{gm}$ instead of $5 \mathrm{gm}$ as maintenance dose). ${ }^{11}$ The lower dose is chosen considering the smaller size for "the Bangladeshi women and concerns about toxicity in circumstances of which measuring serum magnesium levels would be difficult. $^{8}$ Its efficacy in controlling convulsions and preventing recurrences has been established in many prospective studies. ${ }^{9}$ Recently it has also been suggested that -an initial loading dose of $\mathrm{MgSO}_{4}$ is sufficient to arrest convulsion. ${ }^{6}$

$\mathrm{MgSO}_{4}$ is not an innocuous drug. Its therapeutic and toxic dose is very close. It is necessary to monitor the patients who are receiving the medication to prevent serious sideeffects. Duley recommended frequent (every 5 to 10 minutes) monitoring during the first two hours of intravenous regimen. ${ }^{10}$ But the low dose (Dhaka) regimen that is being used in Bangladesh has been found to be associated with serum levels that are well below the toxic levels. ${ }^{9}$

This cross sectional study was carried out with an aim to compare the role and effect of loading dose of magnesium sulfate for control of convulsion in eclampsia determine the effects of loading dose of $\mathrm{MgSO}_{4}$ and loading plus maintenance dose on control of convulsion, the feto-maternal out comes, side effects of magnesium sulfate. The mean $( \pm \mathrm{SD})$ age found in the study was $25.92 \pm 5.63$ years. Maximum number was found in the age group of 26-30 years in the study. Begum et al. (2002) have shown in their series, the mean age of the eclampsia patients was $22.4 \pm 4.21$ years, which is identical with Begum et al. ${ }^{6}$ None of the patients were from the higher socioeconomic status. Sixteen percent of the patient were admitted to the hospital with term (>37 weeks) pregnancy.

The mean $( \pm$ SD) gestational age was $35.14 \pm 2.49$ respectively. As regards to the parity, Begum et al. (2001), Tailor et al. (1998) and Fleischer et al. (1991) found consistent findings in their studies, where the present study it was observed. About one third 15 $(30.00 \%)$ patients were presented in the conscious state respectively $27(54.0 \%)$ in semiconscious and $8(16.0 \%)$ in Unconscious. It was observed that semiconscious 27 $(54.0 \%)$, mild oedema $21(42.0 \%)$ and mild urinary albumin $24(48 \%)$ were predominant. Mean blood pressure was $153.4 \pm 21 .^{6}$ in systolic and $105.0 \pm 14.4$ in diastolic. The mean $( \pm \mathrm{SD})$ number of convulsion (before admission) was $6.08 \pm 1.86$. The mean $( \pm \mathrm{SD})$ convulsion (fit) and admission interval was $5.98 \pm 1.20$. In the mean $( \pm \mathrm{SD})$ convulsion and treatment interval was $6.23 \pm 1.18$ hours. The mean $( \pm \mathrm{SD})$ convulsion (fit) and delivery interval was $7.95 \pm 1.33$. Although $\mathrm{MgSO}_{4}$ is a potent anticonvulsant, in many occasions convulsion recurs. The result of collaborative eclampsia trial shows recurrentconvulsion rate $13.2 \%$ ) and $5.7 \%$ in two controlled trials. ${ }^{2}$ From different studies it has been found that recurrent convulsion is not high in our population. Phuapradit et al found that mean serum magnesium leve1s were significantly lower in women having a weight of $>70 \mathrm{~kg}$ then the level observed in patients with a body weight <70kg. ${ }^{12}$ after a loading dose, the drug is distributed throughout the body specially in skeletal tissues and only a small amount is left in the extracellular fluid. So the patients having lower body volume will have a higher serum drug concentration during treatment with the maintenance regime. ${ }^{13}$ Bangladeshi women are usually lighter and mean body weight of pregnant women is $53 \mathrm{~kg} .{ }^{14}$ This may explain the low rates of recurrent convulsion during $\mathrm{MgSO}_{4}$ therapy. Prichard and coworkers described repeated recurrent convulsions in two women having pre-pregnancy weight of 130 and $180 \mathrm{~kg}$ respectively. In this study, patients, who had recurrent convulsions, were not obese and their blood pressure was also not high at the time of convulsion. Convulsion was controlled by an additional dose of $2.5 \mathrm{gm}$ of $\mathrm{MgSO}_{4}$. Recurrence of convulsion were, found $4(8.00 / 0)$ and number of convulsion one was found in 1 $(2.0 \%)$. However, no. of convulsion two was found 3 $(6.0 \%)$. One hour taken after control of convulsion was 2 $(4.0 \%)$ patients. Two hours taken after control of convulsion was $2(4.00 / 0)$.

Monitoring of the patients to detect the toxicity of $\mathrm{MgSO}_{4}$ in both groups at $1^{\text {st }}$ to $3^{\text {rd }}$ hours and 24 hours after the 
initiation of treatment was done, which is commonest complications in eclamptic patients supported by the Khan. ${ }^{15}$ Regained consciousness was predominant in the both groups about $28(56.0 \%)$ patients after initiation of treatment. Maternal death was found $1(2.00 \%)$. The cause of maternal mortality was due to renal failure. The result obtained in the present study is comparable with Begum et al. (2001). ${ }^{16}$ The mean $( \pm \mathrm{SD})$ respiratory rate was $20.2 \pm 4.19$ minute. Normal urine was found 43 $(86.0 \%)$. Normal knee jerks were found 45 (90.0\%). No toxicity developed in any group assessed by the parameters like respiratory rate, urine volume and knee jerks. The result obtained in the present study is comparable with Begum et al. (2001). ${ }^{16}$

Limitation: Our study wasn't a blinded study so patient bias was present along with observer bias in subjective recording and the limited number of patients, so it is difficult to find out overall significant result. Different types of essential investigations were difficult to do on emergency basis due to lack of investigation facilities. As the serum magnesium level estimation is a very costly and sophisticated test, we did not do this test and mostly, we had to depend on clinical monitoring.

\section{CONCLUSION}

Though there were different preventive approaches to improve obstetrics care in Bangladesh, eclampsia is still responsible for $16 \%$ of the maternal mortality on as national basis. As eclampsia is primarily a convulsive state, present management of eclampsia aims to stop and control the recurrence of convulsion first. The effectiveness of the loading dose of $\mathrm{MgSO}_{4}$ in preventing convulsion is well studied and remarkable. $\mathrm{MgSO}_{4}$ is used only in some tertiary centers like medical colleges by the previous standard regimen. The present study shows that loading dose has some advantage over the standard regimen. Once loading dose is administered, frequent monitoring of the patient is not necessary. So, manpower involvement is less, and as single loading dose can effectively control and prevent recurrent convulsion, patient need not, pay money for the extra amount of $\mathrm{MgSO}_{4}$. For the above reasons, eclampsia can be treated by only loading dose of $\mathrm{MgSO}_{4}$ in primary healthcare centers or before referral to a tertiary hospital. This early intervention will significantly reduce the maternal morbidity and mortality. Finally, we would like to recommend the following measures for the prevention and treatment of eclampsia. A national health programme and action plan to improve and easy access of health facilities (like antenatal care). Establish a protocol of therapy rationale for the eclamptic patients in all healthcare levels, especially $\mathrm{MgSO}_{4} \cdot \mathrm{MgSO}_{4}$ must be made easily available at government level and should be available in government hospitals. Training of healthy personnel in rural areas. Establishment of a fast referral system. Increase awareness among general population about the dreadful disease, eclampsia and its early treatment.
Funding: No funding sources

Conflict of interest: None declared

Ethical approval: The study was approved by the Institutional Ethics Committee

\section{REFERENCES}

1. Robson SC. Hypertension and rena. disease in pregnancy. In: Endmonds OK, editor, Dewhurst's text book of Obstetrics and Gynaecology for postgraduates $6^{\text {th }}$ ed. London: Black well Scientific publications, Black well Scientific Publication. 2000; 166-85.

2. The Eclampsia Trial Collaborative Group, which anticonvulsant for women with eclampsia? Evidence from the collaborative Eclampsia Trial, Lancet. 1995;345(8963):1455-63.

3. Reynoids C, Mabie we, Sibai BM. Hypertensive state pregnancy. In: De cheronsy AH, Nathare I, editors. Current obstetric and gynecologic diagnosis and treatment $10^{\text {th }}$ ed. New York: Lange Medical Book, Me Graw-H ill Med Publish Div. 2007:31827.

4. Mattar F, Shibai 8M, Eclampsia. Risk factors for maternal morbidity. Am J Obstet Gynaec, 2000;182(2):307-12.

5. Alam S, Shamsuddin L, Charabarty GK, Begum M, Islam S. Intravenous Magnesium sulphate in the management of Eclampsia. Bangladesh J. Obstet Gyneco, 2002;17(2):56-9.

6. Begum MR, Begum A, Quadir E. Loading' dose versus standard regime of magnesium sulfate in the management of eclamsia: A randomized trial. Obstet Gyneeco. 2002;28(3):154-9.

7. Hospital Statistics, Rajshahi Medical College Hospital. Rajshahi, Bangladesh.

8. Begum R, Begum A, Johanson R, Ali MN, Akhter S. A low dose ('Dhaka') magnesium sulfate regime for eclampsia. Acta Obstet Gynecol Scand. 2001;80(11):998-1002.

9. Rouf S, Shamsudin L, Khan JH. Magnesium sulfate versus diazepam in the management of eclampsia. Bangladesh J Obstet Gyneco. 1996;11:1-14.

10. Chien PF, Khan KS, Arnott N. Magnesium sulfate in the treatment of eclampsia and pre eclampsia: an overview of the evidence from randomized trials. $\mathrm{Br}$ J Obstet Gynaeco. 1996;103(11):108-91.

11. Eclampsia Working Group, Eclampsia in Bangladesh. A review \& guideline. Bangla J obstet and Gynaec. 1997;12:1-27.

12. Phuapradit W, Saropala N, Haruvasin S, Thuvasethakul P. Serum level of magnesium attained in magnesium sulfate therapy for severe preeclampsia. Asia-Oceania J Obstet and Gynaec. 1993;19(4):387-90.

13. Chesely LC. Parentral magnesium and the distribution, plasma levels and excretion of magnesium. Am J Obstet \& Gynaec. 1979;133(1):17. 
14. Begum R, Bhuiya AB, Tahera S. Incidence of low birth weight baby in Dhaka Medical College and Hospital. Bangla an Obstet Gynaeco. 1995;10(1):2637.

15. Khan $\mathrm{JH} . \mathrm{MgSO}_{4}$ vs diazepam in the management of eclampsia (Dissertation) Dhaka. Bangladesh College of Physi and Surg.
16. Sibai BM. Magnesium sulfate prophylaxis in preeclampsia; Lessons learned from recent trials. Am J Obstet and Gynaec. 2004;190(6):1520-6.

Cite this article as: Khatun H, Islam MS, Islam T. Effective role of the 'loading' dose of magnesium sulfate in the treatment of eclampsia. Int J Reprod Contracept Obstet Gynecol 2021;10:1776-81. 